\title{
Article
}

\section{Suppression of the N1 auditory evoked potential for sounds generated by the upper and lower limbs.}

van Elk, Michiel, Salomon, Roy, Kannape, Oliver and Blanke, Olaf Available at http://clok.uclan.ac.uk/11539/

van Elk, Michiel, Salomon, Roy, Kannape, Oliver ORCID: 0000-0002-2930-4118 and Blanke, Olaf (2014) Suppression of the N1 auditory evoked potential for sounds generated by the upper and lower limbs. Biological Psychology, 102 . pp. 108-17. ISSN 0301-0511

It is advisable to refer to the publisher's version if you intend to cite from the work. http://dx.doi.org/10.1016/j.biopsycho.2014.06.007

For more information about UCLan's research in this area go to http://www.uclan.ac.uk/researchgroups/ and search for <name of research Group>.

For information about Research generally at UCLan please go to http://www.uclan.ac.uk/research/

All outputs in CLoK are protected by Intellectual Property Rights law, including Copyright law. Copyright, IPR and Moral Rights for the works on this site are retained by the individual authors and/or other copyright owners. Terms and conditions for use of this material are defined in the policies page.

\section{CLoK}

Central Lancashire online Knowledge www.clok.uclan.ac.uk

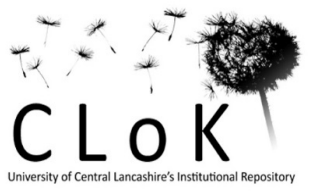


Suppression of the N1 auditory evoked potential for sounds generated by the upper and lower limbs

Michiel van Elk ${ }^{1,2}$, Roy Salomon ${ }^{1,4}$, Oliver Kannape $^{1}$ \& Olaf Blanke ${ }^{1,3,4}$

1. Laboratory of Cognitive Neuroscience

Brain Mind Institute, École Polytechnique Fédérale de Lausanne, Switzerland

2. Department of Psychology, University of Amsterdam, The Netherlands

3. Department of Neurology, University Hospital Geneva, Switzerland

4. Center for Neuroprosthetics, École Polytechnique Fédérale de Lausanne, Switzerland

Corresponding author:

Michiel van Elk

University of Amsterdam

Department of Social Psychology

Weesperplein 4

1018 XA Amsterdam

The Netherlands

Phone: +310205256891

E-mail:m.vanelk@uva.nl 


\section{Abstract}

Sensory attenuation is typically observed for self-generated compared to externally generated action effects. In the present study we investigated whether auditory sensory suppression is modulated as a function of sounds being generated by the upper or lower limbs. We report sensory attenuation, as reflected in a reduced auditory N1 component, which was comparable for sounds generated by the lower and the upper limbs. Increasing temporal delays between actions and sounds did not modulate suppression of the N1 component, but did have an effect on the latency of the N1 component. In contrast, for the P2 component sensory suppression was only observed for sounds generated by the hands and presented at short latencies. These findings provide new insight into the functional and neural dynamics of sensory suppression and suggest the existence of comparable agency mechanisms for both the upper and the lower limbs.

Keywords: Auditory N1; Sensory suppression; EEG; Agency; Upper and lower limbs; Forward models; Efferent copy 


\section{Introduction}

Imagine yourself walking down a dark street at night. When hearing footsteps, it would be important to determine whether these sounds correspond to your own footsteps, or whether these sounds are generated by someone else. As this example illustrates, an important mechanism underlying our everyday actions is the ability to determine whether a specific action-effect is related to our own actions or not. The feeling of agency has been defined as 'the sense that I am the one who is causing or generating an action' (Gallagher, 2000). The feeling of agency is crucial for distinguishing self-generated actions from actions generated by others. As such the neurocognitive mechanisms underlying the feeling of agency may support self-other distinction and may contribute to the subjective feeling of self-awareness (de Vignemont \& Fourneret, 2004; Gallagher, 2000; Pacherie, 2008).

In the last two decades many studies have investigated the functional and neural mechanisms underlying the feeling of agency (for review, see: David, Newen, \& Vogeley, 2008; de Vignemont \& Fourneret, 2004; Kuhn, Brass, \& Haggard, 2012). A prominent model proposed that the feeling of agency relies on the successful integration of predicted and observed action effects through the use of an internal forward model (Blakemore, Wolpert, \& Frith, 2000; Frith, 2005). According to internal forward models of motor control, the brain uses efferent signals from motor-related and / or somatosensory areas to anticipate the sensory consequences of our movements (Wolpert, 1997). The feeling of agency is typically studied by introducing visuo-spatial or temporal deviations between observed and actual movements (Fourneret \& Jeannerod, 1998; Franck et al., 2001; Kannape \& Blanke, 2012; Kannape, Schwabe, Tadi, \& Blanke, 2010; R Salomon, Lim, Kannape, Llobera, \& Blanke, 2013; van den Bos \& Jeannerod, 2002). It has been found for instance, that small visuospatial angular deviations result in an online automatic correction of ongoing movements, that often happens outside awareness (e.g. Fourneret \& Jeannerod, 1998). However, with increased deviations between actual and observed movements the feeling of agency typically decreases and participants deliberately try to correct their movements to adjust the perturbation. Similarly, it has been shown that with increased temporal mismatches between executed and felt touches (applied to one's own body), the sensation of ticklishness increases and it has been argued that this is 
due to the increased difficulty to anticipate the touch (e.g. Blakemore, Frith, \& Wolpert, 1999). It has also been suggested that hallucinations in schizophrenia may be related to an impaired internal forward model, resulting in the feeling that selfgenerated sensations and experiences are actually generated by someone else (Frith, 2005).

The anticipation of the consequences of one's movements has been associated with sensory suppression for self-generated action effects. For instance, selfgenerated touch is perceived as less intense than externally generated identical tactile stimuli (Blakemore et al., 2000) and is associated with reduced activation in somatosensory areas (Blakemore, Wolpert, \& Frith, 1998). Similarly, self-generated sounds and self-generated light flashes are perceived as less intense and are associated with reduced sensory evoked brain responses (for review, see: Hughes, Desantis, \& Waszak, 2012; Hughes \& Waszak, 2011). Animal studies have shown a reduced responsiveness of neurons in the auditory cortex during vocalization (Eliades \& Wang, 2003; Muller-Preuss \& Ploog, 1981). Similar findings have been reported in humans based on intracranial electrode recordings from the auditory cortex during self-produced speech (Creutzfeldt, Ojemann, \& Lettich, 1989). Sensory suppression is strongest for unchanged self-produced speech sounds, but is greatly reduced when auditory feedback is altered (e.g. pitch-shifted sounds; cf. Chen et al., 2012; Christoffels, van de Ven, Waldorp, Formisano, \& Schiller, 2011; Heinks-Maldonado, Mathalon, Gray, \& Ford, 2005; Martikainen, Kaneko, \& Hari, 2005). In all these cases, efferent information is used to anticipate the sensory consequences of one's actions, which results in reduced activation of sensory brain areas for self-generated sounds compared to externally generated sounds (but see: R. Salomon, Szpiro-Grinberg, \& Lamy, 2011).

A well-established neural marker of sensory suppression in the auditory domain is the reduction of the auditory N1 component in the electroencephalogram (EEG) that is typically observed in association with the processing of self-generated compared to externally generated sounds or visual events (Baess, Horvath, Jacobsen, \& Schroger, 2011; Bass, Jacobsen, \& Schroger, 2008; Chen et al., 2012; Gentsch, Kathmann, \& Schutz-Bosbach, 2012; Gentsch \& Schutz-Bosbach, 2011; Martikainen et al., 2005; Sowman, Kuusik, \& Johnson, 2012; Stekelenburg \& Vroomen, 2012). In a 
typical auditory suppression paradigm, participants are instructed to press a button at a regular interval and in 'motor + auditory' blocks, each button press is accompanied by the presentation of an auditory stimulus. In 'auditory-only' blocks, the same sequence of sounds is presented, but the sounds are generated externally while the subject does not move. In the 'motor-only' condition, the participant presses a button but no sounds are presented. In the ERP (event-related potential) analysis the 'motoronly' condition is often subtracted from the 'motor + auditory' condition to control for movement-related effects. Typically, auditory suppression is reflected in a reduced N1 (and often a P2) component for self-generated sounds during the 'motor + auditory' condition compared to externally presented sounds in the 'auditory-only' blocks (Baess et al., 2011; Baess, Widmann, Roye, Schroger, \& Jacobsen, 2009). In a recent study it was found that patients with focal cerebellar lesions showed a reduced sensory suppression for self-generated sounds (Knolle, Schroger, Baess, \& Kotz, 2012). Given the importance of the cerebellum in supporting internal forward models of motor control (Miall, 1998), this finding substantiates the interpretation that auditory suppression reflects a predictive process. More specifically, it is argued that the brain anticipates upcoming sounds based on efferent signals related to the motor commands, which results in a reduced auditory response to anticipated compared to unanticipated stimuli (Bendixen, SanMiguel, \& Schroger, 2012; Hughes \& Waszak, 2011)

Several studies have focused on the different factors that may influence sensory suppression and on several potential confounds that could underlie the effects observed. An obvious concern is that the reduced auditory responses during self-generated sounds are related to increased arousal during preparatory motor processes. However, sensory suppression has also been observed when self-produced and externally generated sounds were intermixed within the same block, thereby making an arousal explanation less likely (Baess et al., 2011; Knolle, Schroger, \& Kotz, 2013). A related concern is that auditory suppression may be related to attentional differences, as early EEG studies have shown that the amplitude of the N1 component is enhanced for attended compared to unattended stimuli (Hillyard, Hink, Schwent, \& Picton, 1973). For instance, in a recent study it was found that mechanical impact (i.e. receiving somatosensory feedback from touching a button) has a substantial effect on 
sensory suppression - possibly through a process whereby attention is directed away from the auditory stream (Horvath, 2014). However, several studies have controlled for the potential confound that attentional effects could underlie sensory suppression (i.e. by manipulating participants' level of attention to the auditory stream) and it was found that sensory suppression is automatic and independent of attention (Saupe, Widmann, Trujillo-Barreto, \& Schroger, 2013; Timm, SanMiguel, Saupe, \& Schroger, 2013). Other studies have controlled for the effects of temporal predictability, for instance by using different temporal delays between the action and the sound and by introducing externally cued sounds (Horvath, Maess, Baess, \& Toth, 2012; Lange, 2011; Sowman et al., 2012). It has been found for instance that N1 suppression decreases with longer stimulus-onset asynchronies (SOAs), whereas P2 suppression was unaffected by the temporal delay (SanMiguel, Todd, \& Schroger, 2013). Furthermore, temporal cueing of sounds resulted in a similar suppression of the auditory P2 component as observed for self-generated sounds (Sowman et al., 2012), indicating that sensory suppression may be partly related to effects of temporal predictability.

Most studies on agency and sensory attenuation have focused selectively on actions involving the upper limbs, by introducing visuo-spatial or temporal mismatches between executed and observed hand actions (Fourneret \& Jeannerod, 1998; Franck et al., 2001; van den Bos \& Jeannerod, 2002) or by presenting sounds in association with hand button presses (for review, see: Hughes, Desantis, \& Waszak, 2013). However, as the example from the introduction illustrates, many of our everyday actions involve other body parts than the upper extremities alone. For instance, we walk, run, swim, jump, kick and each of these actions involves the entire body. It has been suggested that a fundamental aspect of bodily consciousness is that we experience the self as a single coherent representation of the spatially situated body (Blanke \& Metzinger, 2009). Recent studies have shown that this sense of self and the perceived self-location can be experimentally manipulated, by inducing visualtactile or visual-proprioceptive conflicts (Aspell, Lenggenhager, \& Blanke, 2009; Blanke, 2012; Ionta et al., 2011; Lenggenhager, Tadi, Metzinger, \& Blanke, 2007). Interestingly, it has also been shown that people show only limited awareness of their body location during locomotion (Kannape et al., 2010), indicating a similar 
dissociation between the feeling of agency and the actual bodily movements as observed for hand movements (Fourneret \& Jeannerod, 1998). In another study it was found that increased temporal mismatches between one's actual footsteps and experimentally introduced footstep sounds resulted in a decreased feeling of agency and a slower gait cycle (Menzer et al., 2010), also comparable to the effects observed for hand movements (Leube, Knoblich, Erb, \& Kircher, 2003). Similarly, visual feedback presented with a temporal delay also resulted in a decrease in the feeling of agency and systematically modulated the gait cycle (Kannape \& Blanke, 2013). These finding are compatible with the view that planning actions with both the upper and the lower limbs relies on the use of an internal forward model involving an efferent copy, which is used to anticipate the sensory consequences of one's actions (see for instance: Yavari, Towhidkhah, \& Ahmadi-Pajouh, 2013).

Although these studies suggest that comparable functional mechanisms are involved in the feeling of agency for both the upper and lower limbs, other studies indicate important differences in the neural mechanisms supporting hand and foot movements. It is well known that throughout the somatosensory and motor areas the hand and the feet representations are clearly segregated (Disbrow, Roberts, Slutsky, \& Krubitzer, 1999; Schieber, 2001; Young et al., 2004). Many studies have elucidated the neural mechanisms supporting the visuo-motor transformations required for reaching and grasping towards objects, indicating a crucial role for multisensory areas like the middle intraparietal sulcus in guiding upper limb reaching movements (Colby \& Goldberg, 1999; Culham \& Valyear, 2006) or the anterior intraparietal sulcus in preshaping the hand for grasping (AIP; e.g. Grafton, 2010; Jeannerod, Arbib, Rizzolatti, \& Sakata, 1995). The visuo-motor control of the lower limbs relies more strongly on contributions from the cerebellum and the posterior parietal cortex, supporting visually guided locomotion and obstacle avoidance (Drew, Andujar, Lajoie, \& Yakovenko, 2008; Drew, Jiang, \& Widajewicz, 2002). EEG studies have also shown differences in motor-related signals between hand and foot movements, most notably reflected in a polarity reversal of the lateralized readiness potential (LRP) for foot compared to hand movements (Brunia \& van den Bosch, 1984a, 1984b; Miller, 2012). Thus, based on electrophysiological measures the preparation and execution of hand compared to leg movements can be clearly differentiated. 
An important question is whether the neural mechanisms supporting the feeling of agency are effector-independent or also differ between the hands and the feet. Based on behavioral studies showing similar agency-effects for both the upper and the lower limbs (Kannape et al., 2010), and the notion of comparable internal forward models underlying the preparation movements of hands and feet (Yavari et al., 2013), we may expect sensory suppression for sounds generated both by the upper and the lower limbs. In contrast, if sensory suppression is effector-dependent and related to specific efferent signals originating from different motor-related regions (Drew et al., 2008; Drew et al., 2002), we should expect sensory suppression to differ between the upper and the lower limbs. That is, the anticipation of the sensory consequences of a hand movement may be different from those of a feet movement, related to neural differences and differences in our experience with associating specific effects to our actions (Hommel, Musseler, Aschersleben, \& Prinz, 2001). Accordingly, the major aim of the present study was to establish whether similar sensory suppression could be observed for action effects generated by both the upper and the lower limbs.

A related advantage of directly comparing sensory suppression for sounds generated by the hands and the feet is that it allows to assess the relative importance of prior experience for sensory suppression (Horvath et al., 2012; Lange, 2011). All studies on sensory suppression have used sounds that were generated by button presses made by the hand. In daily life we have a profound experience with pressing buttons with our hands (e.g. typing on a keyboard, using a mobile phone etc.) and these actions are typically accompanied by a sound. Previous studies have shown that prior practice with motor-sound contingencies can have a strong effect on the perception of sounds (Repp \& Knoblich, 2007). Accordingly, in all studies on sensory suppression it could well be that sensory suppression is partly related to effectorspecific learning experiences. By directly comparing sounds generated by the upper compared to the lower limbs, this potential confound could be avoided. Furthermore, in many experiments on sensory suppression, the 'motor only' condition is typically subtracted from the 'motor + auditory' condition to control for movement-related effects (Baess et al., 2011; Baess et al., 2009). As movement-related potentials clearly differ between the hands and the feet (Drew et al., 2008; Drew et al., 2002), it can be 
further established whether this classical 'subtraction procedure' provides a valid way to study sensory suppression (i.e. the finding of sensory suppression for both the hands and the feet would indicate that sensory suppression is robust and not affected by movement-related effects).

In this study we measured participants' EEG while they alternately pressed two response buttons with their hands or with their feet. The button presses resulted in the presentation of an auditory stimulus. Auditory responses to self-generated sounds were compared with externally generated sounds, by including a condition in which the sounds were generated by a computer at a predictable - though variable -interval (Aliu, Houde, \& Nagarajan, 2009; Schafer \& Marcus, 1973). In our analysis we focused on both the auditory $\mathrm{N} 1$ and P2 components as a measure of sensory suppression, because previous studies have shown that $\mathrm{N} 1$ suppression is often accompanied by a suppression of the P2 component as well (Baess et al., 2011; Baess et al., 2009; Bass et al., 2008; Behroozmand, Liu, \& Larson, 2011; Ford et al., 2001; Knolle et al., 2012; Schafer \& Marcus, 1973; Sowman et al., 2012). If both the upper and the lower limbs recruit a comparable mechanism of internal forward models we should expect to see a similar sensory suppression for hand-and foot-related sounds, which should be reflected in a reduced $\mathrm{N} 1$ and $\mathrm{P} 2$ component for self-generated compared to externally generated sounds.

In addition to testing sensory suppression effects for the upper and the lower extremities we also investigated to what extent sensory suppression is modulated by the temporal delay between the action and the sound. Previous studies have shown that sensory suppression occurs for self-generated sounds presented at both predictable and unpredictable intervals (Aliu et al., 2009; Bass et al., 2008; Lange, 2011). Furthermore, in a previous study sensory suppression was observed for stimuli presented at both short (i.e. $350 \mathrm{~ms}$ ) and long (i.e. $700 \mathrm{~ms}$ ) latencies between the action and the sound (Lange, 2011). In this study we presented sounds with different delays varying in 250 millisecond steps. For all conditions we also assessed our subjects' feeling of agency, expecting that increased temporal delays between the action and the effect would result in a decreased feeling of agency (cf. Blakemore et al., 1999; Leube et al., 2003; Menzer et al., 2010) and possibly a systematic modulation of the N1 component. In sum, in the present study we investigated how sensory 
suppression is modulated by whether sounds are generated by the upper or lower limbs and by the temporal interval between an action and a subsequent sound. 


\section{Methods}

\subsection{Participants}

In total 12 participants participated in the experiment ( 4 females, mean age $=22.0$ years) all students at the École Polytechnique Fédérale de Lausanne, Switzerland. All participants gave written informed consent before participation and received $50 \mathrm{CHF}$ for participation. The experiment was conducted in accordance with the guidelines from the Declaration of Helsinki.

\subsection{Experimental setup and procedure}

During the experiment participants were seated behind a table and two serial response boxes (Psychology Software Tools, Sharpsburg, USA) were placed near the participant's hands and feet. One response box was attached to the table and one response box was attached to the floor. The pressing of the response buttons was associated with soft clicking sounds, which were subjectively inaudible when wearing the closed headphones that were used for stimulus presentation. We did not include an objective test to control for the potential confound that button presses may have been heard by the participants but we would like to note that this provided a potential concern only for the $0 \mathrm{~ms}$ delay condition, in which the sound coincided with the button press. Both the hands and the feet were covered from view by means of a wooden platform. Auditory stimuli were presented over closed headphones and consisted of $1000 \mathrm{~Hz}$ sine wave sounds of $100 \mathrm{~ms}$ duration (including $10 \mathrm{~ms}$ rise and fall ramps).

During Hand blocks, participants were required to alternately press the left and the right button of the response box with their left and right hand approximately every second. During Foot blocks participants were required to alternately press the left and the right button of the response box with their left and right big toe approximately every second. Each block was repeated 3 times. A different pseudo-randomized blockorder according to a Latin square was used for each participant. ${ }^{1}$

\footnotetext{
${ }^{1}$ In addition to the Hand blocks and the Foot Blocks, also Passive Blocks were included in which participants were instructed to passively hold their hands over the response
} 
Each block consisted of 7 different experimental conditions. In 5 action-sound conditions the button press was always followed by a sound effect at a fixed delay (i.e. $0 \mathrm{~ms}, 250 \mathrm{~ms}, 500 \mathrm{~ms}, 750 \mathrm{~ms}$ and $1000 \mathrm{~ms})$. Participants were instructed to indicate at the end of each action-sound condition whether they believed the sound that was presented corresponded to their button press or not. The experiment was programmed in such a way that button presses were continuously recorded to generate time-stamps for the subsequent presentation of sounds. In this way, we could avoid potential 'missing' sounds because of the participant pressing the button too early (i.e. before the presentation of the corresponding sound).

In the action no-sound condition no sound was presented following the button press. The action no-sound condition was included to control for EEG effects related to preparing and executing a button press during the action-sound conditions (see below). In the external sound condition no buttons were pressed, but a sound was generated by a computer at a jittered interval of $1000+/-200 \mathrm{~ms}$. This interval was chosen to match the other conditions in terms of frequency of stimulus presentation. In each condition, 42 trials were presented and the first 2 trials were used as practice trials. Thus in total, for each experimental condition we obtained 120 trials (3 repetitions per block, 40 repetitions per condition). In total the experiment took about 1.5 hours.

The experiment was programmed using Presentation software (Neurobehavioral systems, Albany, CA, USA) and the timing of the stimuli was handled in $\mathrm{PCL}$ programming, as this allows a more precise control over the timing of the experimental events than SDL. Triggers were sent to the EEG computer in association with button press responses, the onset and the offset of the sounds. Offline inspection of the timing of the markers in the EEG data (i.e. determining the time difference between the button press trigger and the sound trigger) indicated that markers were sent without delay, with an accuracy of $1+/-1$ ms. Accordingly, no offline correction

box, while the experimenter alternately moved their left and right index finger. Data from Passive blocks is not reported in this manuscript, as the primary focus is on the difference between sensory suppression for the hands and feet. 
was required to correct for eventual differences in timing between the button press and the sound.

EEG was recorded at $2048 \mathrm{~Hz}$ using the Active-Two system (BioSemi, Amsterdam, Netherlands), consisting of 64 active electrodes that were placed in an EEG cap according to the standard $10 / 20$ system. The horizontal and vertical EOG was measured by placing electrodes on the outer canthi and above and below the subject's left eye.

\subsection{Data analysis}

For the behavioral analysis we calculated the percentage of 'yes' responses to the question 'Did the sounds correspond to your button press?' for each of the experimental conditions. In addition, for each of the different conditions we calculated the mean inter-response intervals (IRIs). Behavioral data were analyzed using a repeated measures ANOVA with the factors Effector (Hand vs. Foot) and Delay $(0,250,500,750$ and $1000 \mathrm{~ms})$.

For the EEG data analysis, all data was re-referenced to the linked mastoids. For the action-sound and the external-sound conditions data was segmented from 100 to 500 ms relative to stimulus-onset, using a baseline from -100 to $0 \mathrm{~ms}$. For the action no-sound condition in which no sounds were presented 5 different segmentations were conducted (-100 to $500 \mathrm{~ms}, 150$ to $750 \mathrm{~ms}, 400$ to $1000 \mathrm{~ms}, 650$ to $1250 \mathrm{~ms}, 900$ to $1500 \mathrm{~ms}$ relative to the button press). This was done in order to obtain a corresponding epoch that could be used to subtract from each of the actionsound conditions to control for motor-related and somatosensory-related effects (Baess et al., 2011; Chen et al., 2012; ; for critical discussion of this method, see however: Horvath, 2014). Trials that were contaminated by ocular or muscular artifacts were excluded from analysis, based on an automated procedure implemented in Fieldtrip open source software (Oostenveld, Fries, Maris, \& Schoffelen, 2011). EEG data was filtered by using a low-pass filter of $30 \mathrm{~Hz}$ and a high-pass filter of $1 \mathrm{~Hz}$ and was resampled offline to $256 \mathrm{~Hz}$. Grand average ERPs were computed based on the average ERP per subject and per condition.

The average number of trials included for ERP analysis for each condition and each individual subject was analyzed using a repeated measures ANOVA with the 
factors Effector (Hand vs. Foot) and Delay (0 ms, 250 ms, 500 ms, 750 ms, 1000 ms). For hand blocks on average 109 trials (SD = 26) were included per delay condition and for foot blocks on average 110 trials $(S D=28)$ were included per delay condition. No significant differences were observed between the number of trials for hand and foot conditions $(F<1)$. Only a main effect of Delay was observed, $F(4,44)=5.1, p<.005$, $\eta^{2}=.32$, indicating that with longer delays a lower number of artifact-free trials was included. However, this effect was weak in terms of number of trials and was driven by a relatively lower number of trials in the 750 and 1000 ms delay conditions with a difference of only 5 trials compared to the condition with the highest number of trials.

Statistical analysis focused on the interval of the auditory N1 (80-140 ms) and the P2 component ( $140-200 \mathrm{~ms}$ ), which were found maximal over a cluster of frontocentral electrodes (F1, Fz, F2, FC1, FCz, FC2, C1, Cz \& C2). For each subject and for each condition, the peak amplitude and peak latency of the N1 and P2 components were determined within this interval (i.e. automated search for local minimum and local maximum) for the averaged ERP signal across the cluster of fronto-central electrodes and exported for statistical analysis. All statistical analyses were conducted on the ERP data corrected for movement-related effects (i.e. the 'action-no sound' condition was subtracted from the 'action sound' condition). In a first analysis, the ERP data was analyzed using a repeated measures ANOVA with the factor Condition (i.e. 0, 250, 500 , 750, 1000 ms delay conditions and external sound condition). Post-hoc tests were used to determine which of the different delay conditions differed significantly from the external sound conditions. In a second analysis, it was investigated whether sensory suppression differed for actions performed with the hands compared to the feet. To this end, for each condition the sensory suppression of the auditory N1 and $\mathrm{P} 2$ were calculated, by subtracting the active-sound condition from the external sound condition. The resulting values were analyzed using a repeated measures ANOVA with the factors Effector (Hand vs. Foot) and Delay (0, 250, 50, 750 and $1000 \mathrm{~ms}$ ). 


\section{Results}

\subsection{Behavioral Results}

Behavioral data is presented in Figure 1. As can be seen, with increased temporal delays the inter-response intervals (IRI) increased and the feeling of agency (proportion of 'yes' responses) decreased. ${ }^{2}$ For the agency ratings, a main effect of Delay, $F(4,44)=19.0, p<.001, \eta^{2}=.63$, indicated a decreased feeling of agency with increased temporal delays. No interaction was found between Effector and Delay for the Agency ratings, $F(4,44)=1.7, p=.16$. For the IRI a main effect of Delay, $F(4,44)=$ 5.9, $p<.001, \eta^{2}=.35$, was found. Post-hoc tests indicated that in the $0 \mathrm{~ms}$ delay condition the IRI was shorter than in the other conditions, $t(11)>3.0, p<.05$, see Figure 1). No significant interaction was observed between delay and effector.

[INSERT FIGURE 1 ABOUT HERE]

\subsection{Event-related potentials: Hand blocks}

Event-related potentials (ERPs) for the Hand blocks are presented in Figure 2. To obtain an estimate of sensory suppression and to correct for movement-related EEG signals (i.e. movement-related potentials; cf. Neshige, Luders, \& Shibasaki, 1988), the 'action no-sound' condition in which no sound was presented (left plot in Figure 2) was subtracted from each of the 'action-sound' conditions (middle plot in Figure 2).

\footnotetext{
${ }^{2}$ When sounds were presented 1 second after the button had been pressed, the presentation of the sound could coincide with the next button press response. This resulted in the subjective impression that the sound was caused by the current rather than the preceding button press, which is reflected in the behavioral data, indicating a higher proportion of 'yes' responses. For consistency with the other experimental conditions throughout the manuscript we will keep referring to this condition as the '1000 ms delay condition'. We note that the ERP data for the 1000 ms condition needs to be interpreted with caution, as on some trials the presentation of the sound could coincide with a new movement being initiated. For completeness we report all the different temporal delays that were included in the experimental design.
} 
All statistical analyses were conducted on the movement-corrected ERP data (right plot in Figure 2).

Analysis of the $N 1$ amplitude with a repeated measures ANOVA indicated that the $\mathrm{N} 1$ amplitude was significantly modulated by Condition $(0 \mathrm{~ms}, 250 \mathrm{~ms}, 500 \mathrm{~ms}$, $750 \mathrm{~ms}, 1000 \mathrm{~ms}$, external sound), $F(5,55)=3.5, p<.05, \eta^{2}=.19$ (see lower left graph in Figure 2). Post-hoc t-tests indicated a significant difference between the $750 \mathrm{~ms}$ and the external sound condition, $t(11)=2.4, p<.05$, and between the $1000 \mathrm{~ms}$ and the external sound condition, $t(11)=2.7, p<.05$. Condition did also have an effect on the latency of the $\mathrm{N} 1$ component, $F(5,55)=2.6, p<.05, \eta^{2}=.19$ (see $2^{\text {nd }}$ lower graph in Figure 2). Post-hoc t-tests indicated that the latency of the N1 component was longer for the $1000 \mathrm{~ms}$ sound condition, $t(11)=3.5, p<.05$, compared to the external sound condition. For the $0 \mathrm{~ms}$ condition and the $250 \mathrm{~ms}$ condition a statistical trend towards longer latencies was observed, $t(11)=1.9, p=.08$ and $t(11)=2.2, p=.054$ respectively.

Analysis of the $P 2$ amplitude revealed a significant effect of Condition, $F(5,55)=$ $5.3, p<.001, \eta^{2}=.33$ (see $3^{\text {rd }}$ lower graph in Figure 2). Post-hoc t-tests indicated that the 0 ms delay condition, $t(11)=4.9, p<.001$, and the $750 \mathrm{~ms}$ delay condition, $t(11)=$ $2.4, p<.05$, differed significantly from the external sound condition. Analysis of the $P 2$ latency did not show an effect of Condition $(F<1$; see right lower graph in Figure 2).

[INSERT FIGURE 2 ABOUT HERE]

\subsection{Event-related potentials: Foot blocks}

ERPs for the Foot blocks are presented in Figure 3. Similar to the previous analysis, the 'action-no sound' condition (left plot in Figure 3) was subtracted from the 'actionsound' condition (middle plot in Figure 3). All statistical analyses were conducted on the movement-corrected ERP data (right plot in Figure 3).

Analysis of the $N 1$ amplitude with a repeated measures ANOVA revealed a main effect of Condition (0 ms, 250 ms, 500 ms, 750 ms, 1000 ms, external sound), $F(5,55)=3.5, p<.01, \eta^{2}=.24$ (see left lower left graph in Figure 3). Post-hoc t-tests indicated that all conditions differed significantly from the external sound condition 
(only the $500 \mathrm{~ms}$ condition was marginally significant, $t(11)=2.0, p=.07$ ). No effect of condition was found for the latency of the $N 1$ component (see $2^{\text {nd }}$ lower graph in Figure 3).

Analysis of the $P 2$ amplitude revealed a significant effect of Condition, $F(5,55)$ $=2.9, p<.05, \eta^{2}=.21$ (see $3^{\text {rd }}$ lower graph in Figure 3). Post-hoc t-tests indicated a significant difference between the external sound and the $250 \mathrm{~ms}$ condition, $t(11)=$ $3.1, p<.05$, and the external sound and the 500 ms condition, $t(11)=2.4, p<.05$. Analysis of the $P 2$ latency did not show an effect of Condition, $F(5,55)=1.6, p=.14$, $\eta^{2}=.14$, see right lower graph in Figure 3).

\section{[INSERT FIGURE 3 ABOUT HERE]}

\subsection{Event-related potentials: Hand vs. Foot actions}

To investigate to what extent the sensory suppression differed between hand and foot actions an additional analysis was conducted. To this end, for each bock (i.e. Hand Blocks, Foot Blocks) and each experimental condition (auditory delay: $0 \mathrm{~ms}, 250 \mathrm{~ms}$, $500 \mathrm{~ms}, 750 \mathrm{~ms}$ and $1000 \mathrm{~ms}$ ) we calculated the auditory suppression by subtracting the $\mathrm{N} 1$ and the $\mathrm{P} 2$ amplitude for the sound-active conditions from the external-sound conditions (see Figure 4). We compared auditory suppression between hand and foot actions, by analyzing the ERP difference scores, using a 2 (Effector: Hands vs. Feet) $\times 5$ (Delay: $0 \mathrm{~ms}, 250 \mathrm{~ms}, 500 \mathrm{~ms}, 750 \mathrm{~ms}, 1000 \mathrm{~ms}$ ) repeated measures ANOVA. For the auditory N1 no significant interaction was found between Effector and Delay, $F(4,44)$ $=1.8, p=.16, \eta^{2}=.14$, and also the main effects were not significant, $F<1$ (see Figure 4). For the auditory P2, a main effect of Effector was found, $F(1,11)=7.4, p<.05, \eta^{2}$ $=.40$, reflecting that the P2 suppression effect differed between the hands and the feet. A main effect of Delay, $F(4,44)=5.8, p<.01, \eta^{2}=.35$, reflected a stronger P2 suppression for short auditory delays. The interaction between Effector and Delay was not significant, $F(4,44)=1.2, p=.32, \eta^{2}=.10$. 


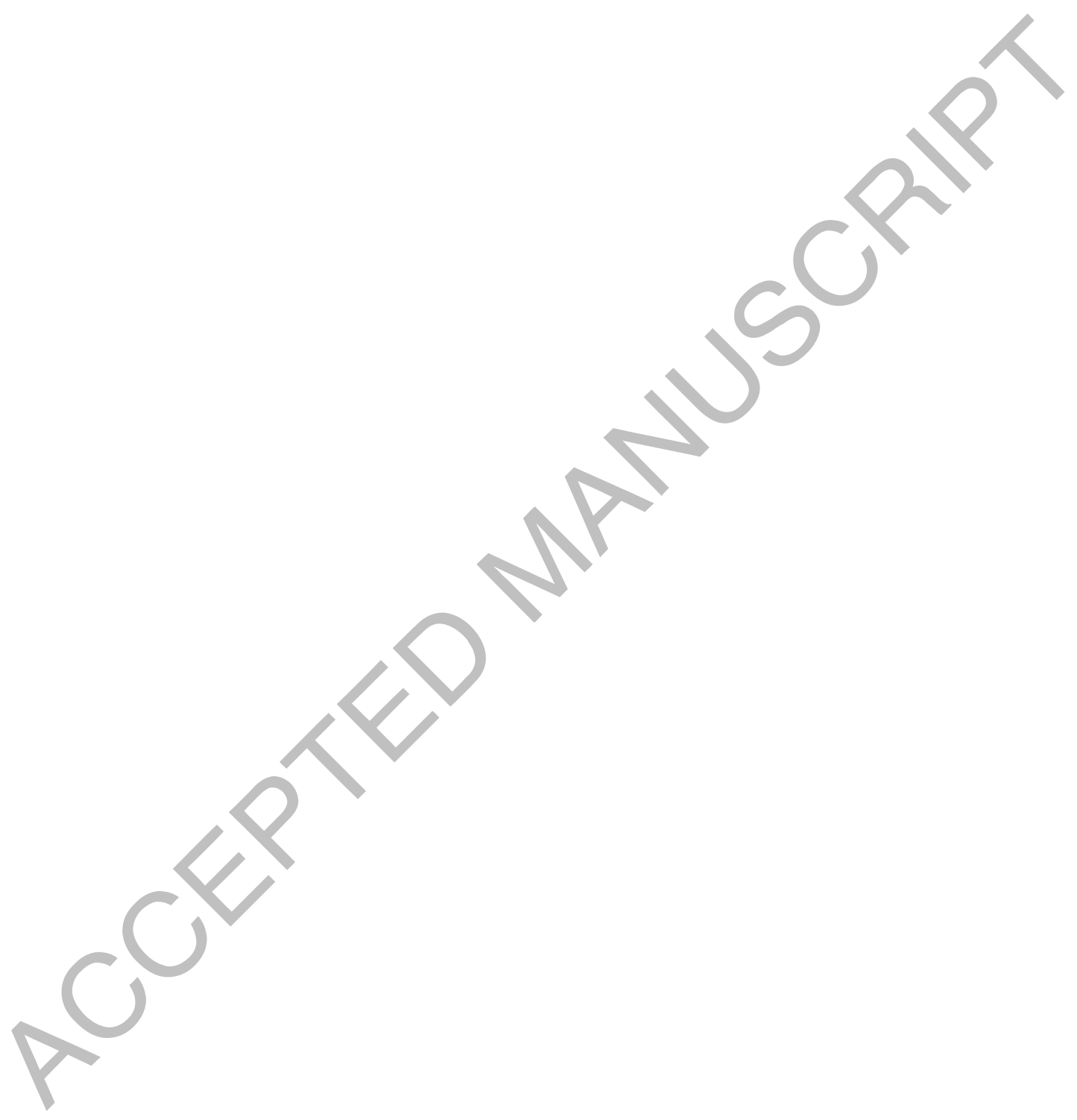




\section{Discussion}

The present study investigated the feeling of agency and its relation to sensory suppression with respect to (1) sounds generated by upper vs. lower limb movements and (2) different temporal delays between the action and the sound. With increased temporal delays the feeling of agency decreased and this effect was comparable for sounds generated by the hands and the feet. For both the upper and the lower limbs we observed sensory suppression as reflected in a reduced N1 component. In addition, we observed sensory suppression for the hands as reflected in a reduced P2 component and this effect was most pronounced at short latencies between the action and the sound. We will discuss the effects of effector type and temporal delay on sensory suppression in more detail below.

For both hand and foot actions the feeling of agency decreased with increased temporal delays between the action and the sound. This finding replicates earlier studies (Leube et al., 2003; Menzer et al., 2010) and suggests that the temporal proximity between executed movements and observed action effects is an important prerequisite for the feeling of agency (Blakemore et al., 1999; Pacherie, 2008). A similar modulation of agency judgments was observed for hand and foot movements, suggesting that the feeling of agency relies on comparable functional mechanisms for both the upper and the lower limbs. More specifically, even though the neural mechanisms supporting the planning and control of hand and foot movements are clearly different (Disbrow et al., 1999; Schieber, 2001; Young et al., 2004), the finding that the feeling of agency was modulated in a comparable fashion as a function of the temporal delays for hands and feet suggests a similar temporal agency mechanism for both the upper and the lower limbs.

The notion of a similar agency mechanisms for hands and feet is supported by the ERP findings as well. For both the upper and the lower limbs we observed an attenuation of the $\mathrm{N} 1$ component for self-generated compared to externally generated sounds, reflecting sensory suppression. Preliminary evidence for the notion that action-effects related to the hands and the feet may be coded in a common format was reported in a study showing a comparable error-related negativity (ERN) for errors resulting from movements by the feet compared to the hands (Holroyd, Dien, \& Coles, 1998). The finding of N1 suppression for the hands and the feet extends 
earlier findings reporting sensory suppression for hand movements (Baess et al., 2011; Bass et al., 2008; Chen et al., 2012; Gentsch et al., 2012; Gentsch \& Schutz-Bosbach, 2011; Horvath et al., 2012; Martikainen et al., 2005; Sowman et al., 2012; Stekelenburg \& Vroomen, 2012) to movements of the lower limbs, suggesting that comparable predictive mechanisms underlie the processing of sensory consequences generated by the hands and the feet.

At present, the precise neural origin of the suppression of the auditory N1 component is a matter of ongoing debate. Some studies have localized the auditory N1 component to the primary auditory cortex / Heschl's gyrus (Godey, Schwartz, de Graaf, Chauvel, \& Liegeois-Chauvel, 2001; Huotilainen et al., 1998; Mulert et al., 2005) and suppression of the auditory $\mathrm{N} 1$ has also been localized to the auditory cortex (Hsu, Hamalainen, \& Waszak, 2014). The suppression of the N1-amplitude for selfgenerated sounds has been argued to reflect a top-down modulation of auditory cortex activity related to efference copy based prediction signals originating from premotor and motor areas, in association with preparing movements with the hands and the feet (Aliu et al., 2009; Baess et al., 2009). However, other studies have indicated that suppression of the N1 component for self-generated sounds is primarily reflected in a reduction of the so-called unspecific N1 component (SanMiguel et al., 2013) that is believed to be generated outside auditory cortex (Naatanen \& Picton, 1987). The notion that auditory suppression is unspecific and reflects a general attenuation of the processing of sensory input is supported by several EEG studies in humans (Hazemann, Audin, \& Lille, 1975; Makeig, Muller, \& Rockstroh, 1996; Tapia, Cohen, \& Starr, 1987) and this effect has been related to changes in auditory processing rather at the sub-cortical level involving multimodal pathways (Aitkin, Dickhaus, Schult, \& Zimmermann, 1978; Szczepaniak \& Moller, 1993). Future studies using combined EEG-fMRI measurements or combined intracranial and extracranial EEG recordings should elucidate the precise neural origin of the N1 suppression effect and whether this involves a top-down regulation of the primary auditory cortex or alternative multisensory pathways.

We observed sensory suppression of the N1 component for sounds generated by the hands and the feet, irrespective of the temporal delay between the action and the sound effect. That is, no interaction was found between effector and delay for the 
N1 component. The finding that N1 sensory suppression occurs irrespective of the temporal delay between one's actions and the sensory consequences, extends earlier studies that have shown that sensory suppression occurs at both short and longer intervals between an action and its sensory consequences (Aliu et al., 2009; Bass et al., 2008; Lange, 2011). These findings indicate that the brain is well able to predict upcoming stimuli based on efferent motor information, even when the sensory consequence does not immediately follow the action. ${ }^{3}$ In addition, whereas a previous study suggested that it takes considerable training before action-sound temporal contingencies can be learned (Aliu et al., 2009), the present findings indicate that these associations develop quickly, already after a few trials. ${ }^{4}$ An interesting question to be addressed in future studies concerns the upper limit of sensory suppression. In the present study participants were always presented with intervals between their action and a sound of a maximum duration of 1 second, but it could well be that the brain is able to anticipate sensory consequences beyond this timeinterval as well.

Previous studies have shown that the suppression of the N1 component is often accompanied by a suppression of the P2 component as well (Baess et al., 2011; Baess et al., 2009; Bass et al., 2008; Behroozmand et al., 2011; Ford et al., 2001; Knolle et al., 2012; Schafer \& Marcus, 1973; Sowman et al., 2012). In the present study we only observed a reduced P2 amplitude for self-generated compared to externally generated sounds for hand actions, when there was no delay between the action and the sound. The observed dissociation between the effects of N1 and P2 suppression is in line with other studies, showing a similar functional dissociation between these

${ }^{3}$ It could be that this finding is a logical consequence of the experimental design that was used, in which the temporal delay was always fixed and as such predictable within blocks. A variable and unpredictable delay may have resulted in different effects.

${ }^{4}$ It should be noted that the subjective reports by the participants indicated that most participants were well aware of the fact that in some conditions the auditory feedback from their movements was systematically delayed with a constant interval. This knowledge may have actually helped them to accurately predict the onset of the auditory stimuli for each of the different conditions. 
components (Ford et al., 2001; Horvath et al., 2012; Knolle et al., 2012). For instance, patients with cerebellar lesions were characterized by a reduced N1-suppression effect, but the P2-suppression effect was comparable to control participants (Knolle et al., 2012). It has been suggested that the P2 reflects the processing of the specific features of acoustic stimuli (Shahin, Roberts, Pantev, Trainor, \& Ross, 2005) and is sensitive to top- down modulations such as memory and training (Ross \& Tremblay, 2009). Accordingly, it could well be that the selective P2 suppression for hand actions primarily reflects learned associations between hand actions and subsequent sounds. For the feet and for longer temporal delays, these associations have become less well established and accordingly no modulation of the P2 component was observed for these actions.

In the present study the inter-stimulus interval was kept constant, but the auditory delay between the action and the sound was systematically manipulated. It was found that the auditory delay did not modulate sensory suppression, but interestingly an effect on the latency of the N1 component was observed. That is, with longer intervals between the action and the sound the N1 latency decreased. This finding indicates that the brain may anticipate the sensory consequences of one's actions by adjusting the temporal dynamics of sensory processing. This finding is in line with previous studies that have reported a modulation of the latency of the N1 component (or the M100 component) for self-generated compared to externally generated sounds as well (Curio, Neuloh, Numminen, Jousmaki, \& Hari, 2000; Houde, Nagarajan, Sekihara, \& Merzenich, 2002; Lange, 2011). It is well established that the brain generates a sense of agency through a process of 'intentional binding', whereby the sensory consequences of one's actions are perceived to be in closer temporal proximity to one's action than they actually are (Moore \& Haggard, 2010). A similar process could play a role in the present study, in which the brain is faster in detecting and processing sounds presented at intermediate delays, likely because of a process of building up sensory expectations regarding the temporal occurrence of an upcoming stimulus (e.g. Lange, 2011; Melloni, Schwiedrzik, Muller, Rodriguez, \& Singer, 2011).

Recently, it has been found that the N1 suppression for self-generated sounds was most pronounced for sounds presented at long stimulus-onset-asynchronies 
(SOAs), with the strongest suppression being observed for sounds presented every 3.2 seconds and the smallest suppression for sounds presented every .8 seconds (SanMiguel et al., 2013). This finding supports the notion that the N1 suppression effect primarily reflects suppression of the unspecific N1 component (i.e. N1bU), which is typically only obtained for sounds that are presented at longer SOAs (Naatanen \& Picton, 1987). In contrast, in the present study a relatively short interstimulus interval was used (i.e. a sound was presented approximately every second) and the finding of sensory suppression replicates earlier studies that have also used such higher stimulus presentation rate (Baess et al., 2009; Ford et al., 2001; van Elk, Lenggenhager, Heydrich, \& Blanke, 2014). As we did not include stimuli being presented at different SOAs (i.e. the pace at which the response button was being pressed was kept constant) the present paradigm does not allow to determine whether the suppression affected mainly the unspecific N1 component or the earlier components of the $\mathrm{N} 1$ as well (e.g. the N1bT originating from primary auditory cortex). Still, the finding of sensory suppression for stimuli being presented at a fast presentation rate indicates the feasibility of using experimental paradigms on sensory suppression, in which stimuli are presented at a higher rate thereby reducing the total experimental duration (van Elk et al., 2014).

\section{Conclusions}

The present study shows sensory suppression for sounds generated by both the upper and the lower extremities, reflected in an attenuation of the N1 amplitude for selfgenerated compared to externally generated sounds. These findings provide new insight in the functional and neural dynamics of sensory suppression and suggest the existence of comparable agency mechanisms for both the upper and the lower limbs. 


\section{Acknowledgments}

The present study was supported by the Marie Curie Intra European Fellowship within the Seventh European Community Framework Program (IEF grant 252713 to MVE) and the Dutch Science Organization (VENI grant no. 016.135.135). OB is supported by the Swiss National Science foundation, the European Science Foundation, and the Fondation Bertarelli. Roy Salomon was supported by the National Center of Competence in Research (NCCR) "SYNAPSY-The Synaptic Bases of Mental Diseases" financed by the Swiss National Science Foundation (n51AU40_125759).

\section{References}

Aitkin, L. M., Dickhaus, H., Schult, W., \& Zimmermann, M. (1978). External Nucleus of Inferior Colliculus - Auditory and Spinal Somatosensory Afferents and Their Interactions. Journal of Neurophysiology, 41(4), 837-847.

Aliu, S. O., Houde, J. F., \& Nagarajan, S. S. (2009). Motor-induced suppression of the auditory cortex. Journal of Cognitive Neuroscience, 21(4), 791-802.

Aspell, J. E., Lenggenhager, B., \& Blanke, O. (2009). Keeping in touch with one's self: multisensory mechanisms of self-consciousness. PLoS One, 4(8), e6488.

Baess, P., Horvath, J., Jacobsen, T., \& Schroger, E. (2011). Selective suppression of selfinitiated sounds in an auditory stream: An ERP study. Psychophysiology, 48(9), 12761283.

Baess, P., Widmann, A., Roye, A., Schroger, E., \& Jacobsen, T. (2009). Attenuated human auditory middle latency response and evoked $40-\mathrm{Hz}$ response to self-initiated sounds. European Journal of Neuroscience, 29(7), 1514-1521.

Bass, P., Jacobsen, T., \& Schroger, E. (2008). Suppression of the auditory N1 eventrelated potential component with unpredictable self-initiated tones: evidence for internal forward models with dynamic stimulation. International Journal for Psychophysiology, 70(2), 137-143.

Behroozmand, R., Liu, H. J., \& Larson, C. R. (2011). Time-dependent Neural Processing of Auditory Feedback during Voice Pitch Error Detection. Journal of Cognitive Neuroscience, 23(5), 1205-1217.

Bendixen, A., SanMiguel, I., \& Schroger, E. (2012). Early electrophysiological indicators for predictive processing in audition: A review. International Journal of Psychophysiology, 83(2), 120-131.

Blakemore, S. J., Frith, C. D., \& Wolpert, D. M. (1999). Spatio-temporal prediction modulates the perception of self-produced stimuli. Journal of Cognitive Neuroscience, 11(5), 551-559.

Blakemore, S. J., Wolpert, D., \& Frith, C. D. (2000). Why can't you tickle yourself? Neuroreport, 11(11), R11-16.

Blakemore, S. J., Wolpert, D. M., \& Frith, C. D. (1998). Central cancellation of selfproduced tickle sensation. Nature Neuroscience, 1(7), 635-640.

Blanke, O. (2012). Multisensory brain mechanisms of bodily self-consciousness. Nature Reviews Neuroscience, 13(8), 556-571. 
Blanke, O., \& Metzinger, T. (2009). Full-body illusions and minimal phenomenal selfhood. Trends in Cognitive Sciences, 13(1), 7-13.

Brunia, C. H., \& van den Bosch, W. E. (1984a). The influence of response side on the readiness potential prior to finger and foot movements. A preliminary report. Annals of the New York Academy of Sciences, 425, 434-437.

Brunia, C. H., \& Van den Bosch, W. E. (1984b). Movement-related slow potentials. I. A contrast between finger and foot movements in right-handed subjects. Electroencephalography and Clinical Neurophysiology, 57(6), 515-527.

Chen, Z., Liu, P., Wang, E. Q., Larson, C. R., Huang, D., \& Liu, H. (2012). ERP correlates of language-specific processing of auditory pitch feedback during self-vocalization. Brain and Language, 121(1), 25-34.

Christoffels, I. K., van de Ven, V., Waldorp, L. J., Formisano, E., \& Schiller, N. O. (2011). The sensory consequences of speaking: parametric neural cancellation during speech in auditory cortex. PLoS One, 6(5), e18307.

Colby, C. L., \& Goldberg, M. E. (1999). Space and attention in parietal cortex. Annual Reviews of Neuroscience, 22, 319-349.

Creutzfeldt, O., Ojemann, G., \& Lettich, E. (1989). Neuronal activity in the human lateral temporal lobe. II. Responses to the subjects own voice. Experimental Brain Research, 77(3), 476-489.

Culham, J. C., \& Valyear, K. F. (2006). Human parietal cortex in action. Current Opinions in Neurobiology, 16(2), 205-212.

Curio, G., Neuloh, G., Numminen, J., Jousmaki, V., \& Hari, R. (2000). Speaking modifies voice-evoked activity in the human auditory cortex. Human Brain Mapping, 9(4), 183191.

David, N., Newen, A., \& Vogeley, K. (2008). The "sense of agency" and its underlying cognitive and neural mechanisms. Consciousness and Cognition, 17(2), 523-534.

de Vignemont, F., \& Fourneret, P. (2004). The sense of agency: a philosophical and empirical review of the "Who" system. Consciousness and Cognition, 13(1), 1-19.

Disbrow, E., Roberts, T. P., Slutsky, D., \& Krubitzer, L. (1999). The use of fMRI for determining the topographic organization of cortical fields in human and nonhuman primates. Brain Research, 829(1-2), 167-173.

Drew, T., Andujar, J. E., Lajoie, K., \& Yakovenko, S. (2008). Cortical mechanisms involved in visuomotor coordination during precision walking. Brain Research Reviews, 57(1), 199-211.

Drew, T., Jiang, W., \& Widajewicz, W. (2002). Contributions of the motor cortex to the control of the hindlimbs during locomotion in the cat. Brain Research and Brain Research Reviews, 40(1-3), 178-191.

Eliades, S. J., \& Wang, X. (2003). Sensory-motor interaction in the primate auditory cortex during self-initiated vocalizations. Journal of Neurophysiology, 89(4), 21942207.

Ford, J. M., Mathalon, D. H., Heinks, T., Kalba, S., Faustman, W. O., \& Roth, W. T. (2001). Neurophysiological evidence of corollary discharge dysfunction in schizophrenia. American Journal of Psychiatry, 158(12), 2069-2071.

Fourneret, P., \& Jeannerod, M. (1998). Limited conscious monitoring of motor performance in normal subjects. Neuropsychologia, 36(11), 1133-1140. 
Franck, N., Farrer, C., Georgieff, N., Marie-Cardine, M., Dalery, J., d'Amato, T., et al. (2001). Defective recognition of one's own actions in patients with schizophrenia. American Journal of Psychiatry, 158(3), 454-459.

Frith, C. (2005). The neural basis of hallucinations and delusions. Comptes rendus biologies, 328(2), 169-175.

Gallagher, I. I. (2000). Philosophical conceptions of the self: implications for cognitive science. Trends in Cognitive Sciences, 4(1), 14-21.

Gentsch, A., Kathmann, N., \& Schutz-Bosbach, S. (2012). Reliability of sensory predictions determines the experience of self-agency. Behavioral and Brain Research, 228(2), 415-422.

Gentsch, A., \& Schutz-Bosbach, S. (2011). I did it: unconscious expectation of sensory consequences modulates the experience of self-agency and its functional signature. Journal of Cognitive Neuroscience, 23(12), 3817-3828.

Godey, B., Schwartz, D., de Graaf, J. B., Chauvel, P., \& Liegeois-Chauvel, C. (2001). Neuromagnetic source localization of auditory evoked fields and intracerebral evoked potentials: a comparison of data in the same patients. Clinical Neurophysiology, 112(10), 1850-1859.

Grafton, S. T. (2010). The cognitive neuroscience of prehension: recent developments. Experimental Brain Research, 204(4), 475-491.

Hazemann, P., Audin, G., \& Lille, F. (1975). Effect of Voluntary Self-Paced Movements Upon Auditory and Somatosensory Evoked-Potentials in Man. Electroencephalography and Clinical Neurophysiology, 39(3), 247-254.

Heinks-Maldonado, T. H., Mathalon, D. H., Gray, M., \& Ford, J. M. (2005). Fine-tuning of auditory cortex during speech production. Psychophysiology, 42(2), 180-190.

Hillyard, S. A., Hink, R. F., Schwent, V. L., \& Picton, T. W. (1973). Electrical signs of selective attention in the human brain. Science, 182(4108), 177-180.

Holroyd, C. B., Dien, J., \& Coles, M. G. (1998). Error-related scalp potentials elicited by hand and foot movements: evidence for an output-independent error-processing system in humans. Neuroscience Letters, 242(2), 65-68.

Hommel, B., Musseler, J., Aschersleben, G., \& Prinz, W. (2001). The Theory of Event Coding (TEC): A framework for perception and action planning. Behavioral and Brain Sciences, 24(5), 849-878.

Horvath, J. (2014). The role of mechanical impact in action-related auditory attenuation. Cognitive and Affective Behavioral Neuroscience, advance online publication, 1-15.

Horvath, J., Maess, B., Baess, P., \& Toth, A. (2012). Action-sound coincidences suppress evoked responses of the human auditory cortex in EEG and MEG. Journal of Cognitive Neuroscience, 24(9), 1919-1931.

Houde, J. F., Nagarajan, S. S., Sekihara, K., \& Merzenich, M. M. (2002). Modulation of the auditory cortex during speech: An MEG study. Journal of Cognitive Neuroscience, 14(8), 1125-1138.

Hsu, Y. F., Hamalainen, J. A., \& Waszak, F. (2014). Both attention and prediction are necessary for adaptive neuronal tuning in sensory processing. Frontiers in Human Neuroscience, 8.

Hughes, G., Desantis, A., \& Waszak, F. (2012). Mechanisms of Intentional Binding and Sensory Attenuation: The Role of Temporal Prediction, Temporal Control, Identity Prediction, and Motor Prediction. Psychological Bullettin. 
Hughes, G., Desantis, A., \& Waszak, F. (2013). Mechanisms of Intentional Binding and Sensory Attenuation: The Role of Temporal Prediction, Temporal Control, Identity Prediction, and Motor Prediction. Psychological Bullettin, 139(1), 131-151.

Hughes, G., \& Waszak, F. (2011). ERP correlates of action effect prediction and visual sensory attenuation in voluntary action. Neuroimage, 56(3), 1632-1640.

Huotilainen, M., Winkler, I., Alho, K., Escera, C., Virtanen, J., Ilmoniemi, R. J., et al. (1998). Combined mapping of human auditory EEG and MEG responses. Electroencephalography and Clinical Neurophysiology, 108(4), 370-379.

Ionta, S., Heydrich, L., Lenggenhager, B., Mouthon, M., Fornari, E., Chapuis, D., et al. (2011). Multisensory mechanisms in temporo-parietal cortex support self-location and first-person perspective. Neuron, 70(2), 363-374.

Jeannerod, M., Arbib, M. A., Rizzolatti, G., \& Sakata, H. (1995). Grasping objects: the cortical mechanisms of visuomotor transformation. Trends in Neurosciences, 18(7), 314-320.

Kannape, O., \& Blanke, O. (2012). Agency, gait and self-consciousness. International Journal of Psychophysiology, 83(2), 191-199.

Kannape, O., \& Blanke, O. (2013). Self in motion: Sensorimotor and cognitive mechanisms in gait agency. Journal of Neurophysiology, 110(8), 1837-1847.

Kannape, O., Schwabe, L., Tadi, T., \& Blanke, O. (2010). The limits of agency in walking humans. Neuropsychologia, 48(6), 1628-1636.

Knolle, F., Schroger, E., Baess, P., \& Kotz, S. A. (2012). The Cerebellum Generates Motor-to-Auditory Predictions: ERP Lesion Evidence. Journal of Cognitive Neuroscience, 24(3), 698-706.

Knolle, F., Schroger, E., \& Kotz, S. A. (2013). Prediction errors in self- and externallygenerated deviants. Biological Psychology, 92(2), 410-416.

Kuhn, S., Brass, M., \& Haggard, P. (2012). Feeling in control: Neural correlates of experience of agency. Cortex.

Lange, K. (2011). The reduced N1 to self-generated tones: an effect of temporal predictability? Psychophysiology, 48(8), 1088-1095.

Lenggenhager, B., Tadi, T., Metzinger, T., \& Blanke, O. (2007). Video ergo sum: manipulating bodily self-consciousness. Science, 317(5841), 1096-1099.

Leube, D. T., Knoblich, G., Erb, M., \& Kircher, T. T. (2003). Observing one's hand become anarchic: an $\mathrm{fMRI}$ study of action identification. Consciousness and Cognition, 12(4), 597-608.

Makeig, S., Muller, M. M., \& Rockstroh, B. (1996). Effects of voluntary movements on early auditory brain responses. Experimental Brain Research, 110(3), 487-492.

Martikainen, M. H., Kaneko, K., \& Hari, R. (2005). Suppressed responses to selftriggered sounds in the human auditory cortex. Cerebral Cortex, 15(3), 299-302.

Melloni, L., Schwiedrzik, C. M., Muller, N., Rodriguez, E., \& Singer, W. (2011). Expectations Change the Signatures and Timing of Electrophysiological Correlates of Perceptual Awareness. Journal of Neuroscience, 31(4), 1386-1396.

Menzer, F., Brooks, A., Halje, P., Faller, C., Vetterli, M., \& Blanke, O. (2010). Feeling in control of your footsteps: Conscious gait monitoring and the auditory consequences of footsteps. Cognitive Neuroscience, 1(3), 184-192.

Miall, R. C. (1998). The cerebellum, predictive control and motor coordination. Sensory Guidance of Movement, 218, 272-290. 
Miller, J. (2012). Selection and preparation of hand and foot movements: Cz activity as a marker of limb system preparation. Psychophysiology, 49(5), 590-603.

Moore, J. W., \& Haggard, P. (2010). Intentional binding and higher order agency experience. Consciousness and Cognition, 19(1), 490-491.

Mulert, C., Jager, L., Propp, S., Karch, S., Stormann, S., Pogarell, O., et al. (2005). Sound level dependence of the primary auditory cortex: Simultaneous measurement with 61-channel EEG and fMRI. Neuroimage, 28(1), 49-58.

Muller-Preuss, P., \& Ploog, D. (1981). Inhibition of auditory cortical neurons during phonation. Brain Research, 215(1-2), 61-76.

Naatanen, R., \& Picton, T. (1987). The N1 Wave of the Human Electric and Magnetic Response to Sound - a Review and an Analysis of the Component Structure. Psychophysiology, 24(4), 375-425.

Neshige, R., Luders, H., \& Shibasaki, H. (1988). Recording of movement-related potentials from scalp and cortex in man. Brain, 111 ( Pt 3), 719-736.

Oostenveld, R., Fries, P., Maris, E., \& Schoffelen, J. M. (2011). FieldTrip: Open source software for advanced analysis of MEG, EEG, and invasive electrophysiological data. Computional Intelligent Neuroscience, 2011, 156869.

Pacherie, E. (2008). The phenomenology of action: a conceptual framework. Cognition, 107(1), 179-217.

Repp, B. H., \& Knoblich, G. (2007). Action can affect auditory perception. Psychological Science, 18(1), 6-7.

Salomon, R., Lim, M., Kannape, O., Llobera, J., \& Blanke, O. (2013). "Self pop-out": agency enhances self-recognition in visual search. Experimental brain research, 1-9.

Salomon, R., Szpiro-Grinberg, S., \& Lamy, D. (2011). Self-motion holds a special status in visual processing. PLoS One, 6(10), e24347.

SanMiguel, I., Todd, J., \& Schroger, E. (2013). Sensory suppression effects to selfinitiated sounds reflect the attenuation of the unspecific N1 component of the auditory ERP. Psychophysiology, 50(4), 334-343.

Saupe, K., Widmann, A., Trujillo-Barreto, N. J., \& Schroger, E. (2013). Sensorial suppression of self-generated sounds and its dependence on attention. International Journal of Psychophysiology, 90(3), 300-310.

Schafer, E. W., \& Marcus, M. M. (1973). Self-stimulation alters human sensory brain responses. Science, 181(4095), 175-177.

Schieber, M. H. (2001). Constraints on somatotopic organization in the primary motor cortex. Journal of Neurophysiology, 86(5), 2125-2143.

Sowman, P. F., Kuusik, A., \& Johnson, B. W. (2012). Self-initiation and temporal cueing of monaural tones reduce the auditory $\mathrm{N} 1$ and P2. Experimental Brain Research, 222(1-2), 149-157.

Stekelenburg, J. J., \& Vroomen, J. (2012). Electrophysiological correlates of predictive coding of auditory location in the perception of natural audiovisual events. Frontiers in Integrative Neuroscience, 6, 26.

Szczepaniak, W. S., \& Moller, A. R. (1993). Interaction between Auditory and Somatosensory Systems - a Study of Evoked-Potentials in the Inferior Colliculus. Electroencephalography and Clinical Neurophysiology, 88(6), 508-515.

Tapia, M. C., Cohen, L. G., \& Starr, A. (1987). Attenuation of Auditory-Evoked Potentials during Voluntary Movement in Man. Audiology, 26(6), 369-373. 
Timm, J., SanMiguel, I., Saupe, K., \& Schroger, E. (2013). The N1-suppression effect for self-initiated sounds is independent of attention. Bmc Neuroscience, 14.

van den Bos, E., \& Jeannerod, M. (2002). Sense of body and sense of action both contribute to self-recognition. Cognition, 85(2), 177-187.

van Elk, M., Lenggenhager, B., Heydrich, L., \& Blanke, O. (2014). Suppression of the auditory N1-component for heartbeat-related sounds reflects interoceptive predictive coding. Biological Psychology, 99, 172-182.

Wolpert, D. M. (1997). Computational approaches to motor control. Trends in Cognitive Sciences, 1(6), 209-216.

Yavari, F., Towhidkhah, F., \& Ahmadi-Pajouh, M. A. (2013). Are fast/slow process in motor adaptation and forward/inverse internal model two sides of the same coin? Medical Hypotheses, 81(4), 592-600.

Young, J. P., Herath, P., Eickhoff, S., Choi, J., Grefkes, C., Zilles, K., et al. (2004). Somatotopy and attentional modulation of the human parietal and opercular regions. Journal of Neuroscience, 24(23), 5391-5399. 
Figure Captions
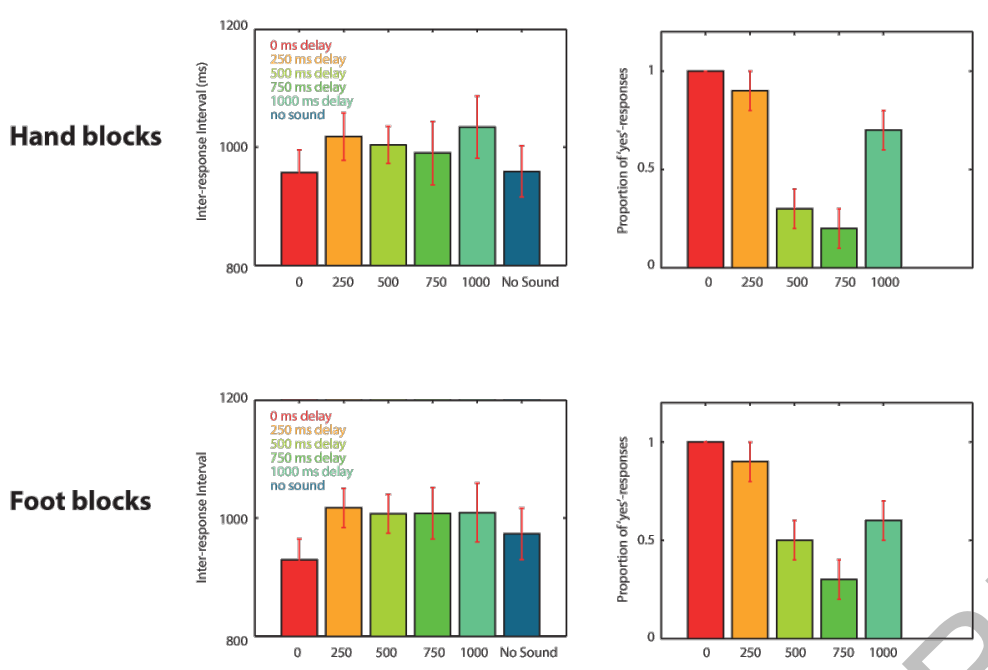

Figure 1: Behavioral results for the different experimental conditions. The upper part of the table represents data from Hand blocks, the lower part from Foot blocks. The left graphs represent the inter-response intervals (IRIS) and the right graphs represent the proportion of 'yes' responses to the question 'Did the sound correspond to your button press?' Different colors represent the different experimental conditions (i.e. 0 $m s=0 m s$ delay between action and sound etc., 'no sound' = condition in which no sounds were presented). 

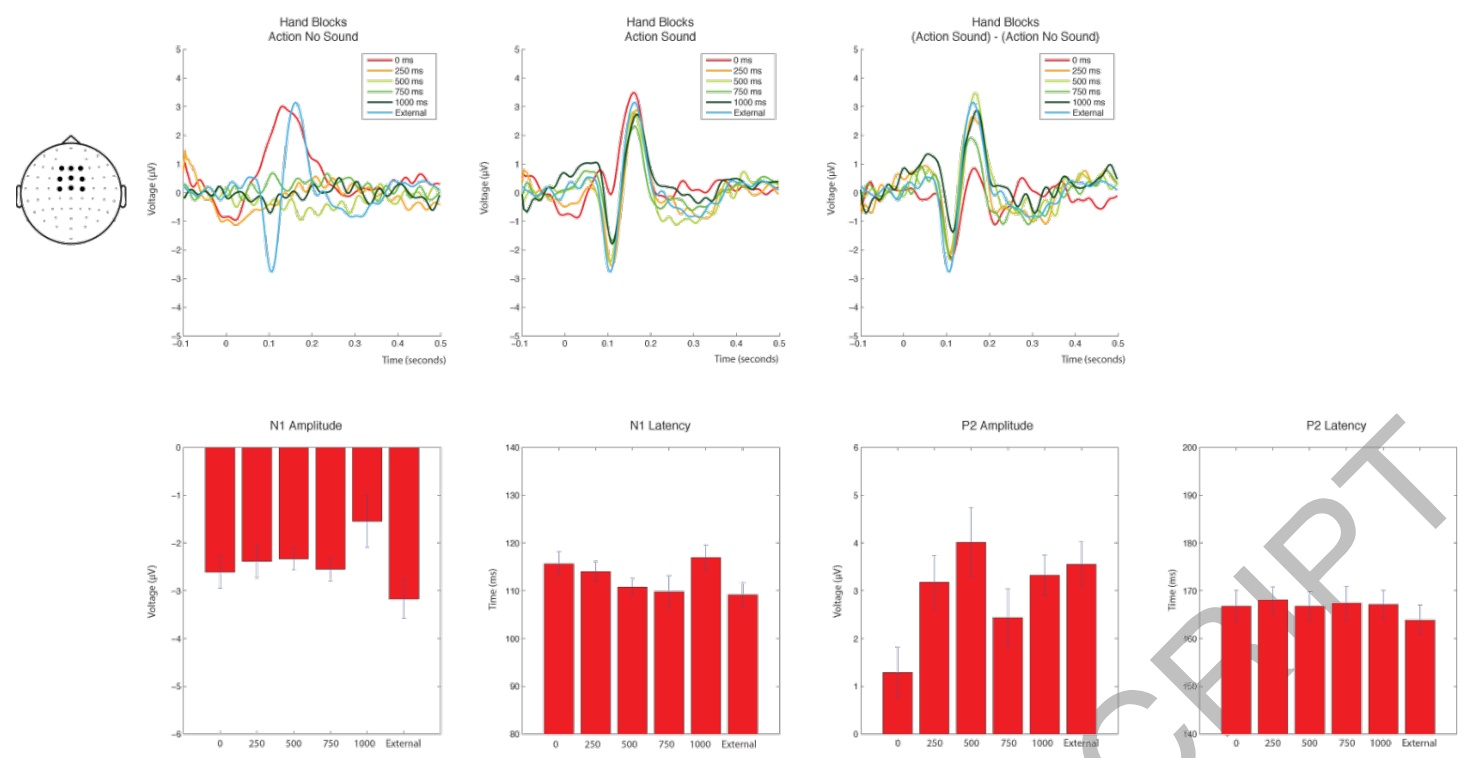

Figure 2: Event-related potentials for Hand blocks. The upper graphs represent the ERPs for Hand Blocks for the 'Action-no sound' condition (left graph), the 'Action-sound' conditions (middle graph) and the difference between the 'Action-sound' and the 'Action-no-sound' conditions (right graph). The topoplot indicates the cluster of electrodes that was used in the ERP analysis. The lower plot represents the N1 peak amplitude (left graph), the N1 peak latency (second graph), the P2 peak amplitude (third graph) and the P2 peak latency (right graph) for the different experimental conditions. Different colors represent the different experimental conditions (i.e. $0 \mathrm{~ms}=$ 0 ms delay between action and sound etc., 'External' = condition in which sounds were externally generated by the computer without a button press). Error bars represent standard errors. All statistical analyses were conducted on the ERP data corrected for movement-related effects (i.e. the 'action-no sound' condition was subtracted from the 'action sound' condition). 


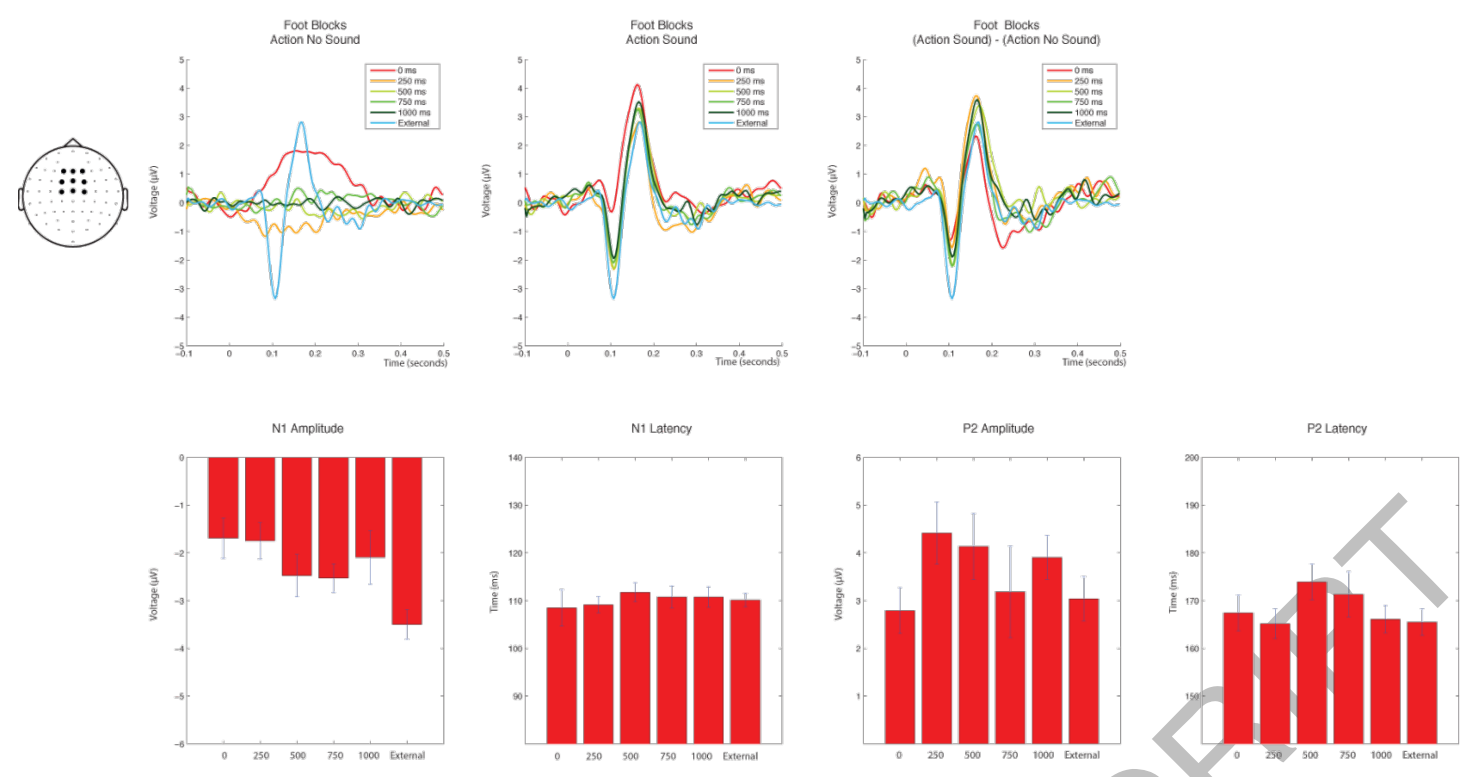

Figure 3: Event-related potentials for Foot blocks. The upper graphs represent the ERPs for Foot blocks, separately for the 'Action-no sound' condition (left graph), the 'Action-sound' conditions (middle graph) and the difference between the 'Actionsound' and the 'Action-no sound' conditions (right graph). The topoplot indicates the cluster of electrodes that was used in the ERP analysis. The lower plot represents the N1 peak amplitude (left graph), the N1 peak latency (second graph), the P2 peak amplitude (third graph) and the P2 peak latency (right graph) for the different experimental conditions (i.e. $0 \mathrm{~ms}=0 \mathrm{~ms}$ delay between action and sound etc., 'External' = condition in which sounds were externally generated by the computer without a button press). Error bars represent standard errors. All statistical analyses were conducted on the ERP data corrected for movement-related effects (i.e. the 'action-no sound' condition was subtracted from the 'action sound' condition). 

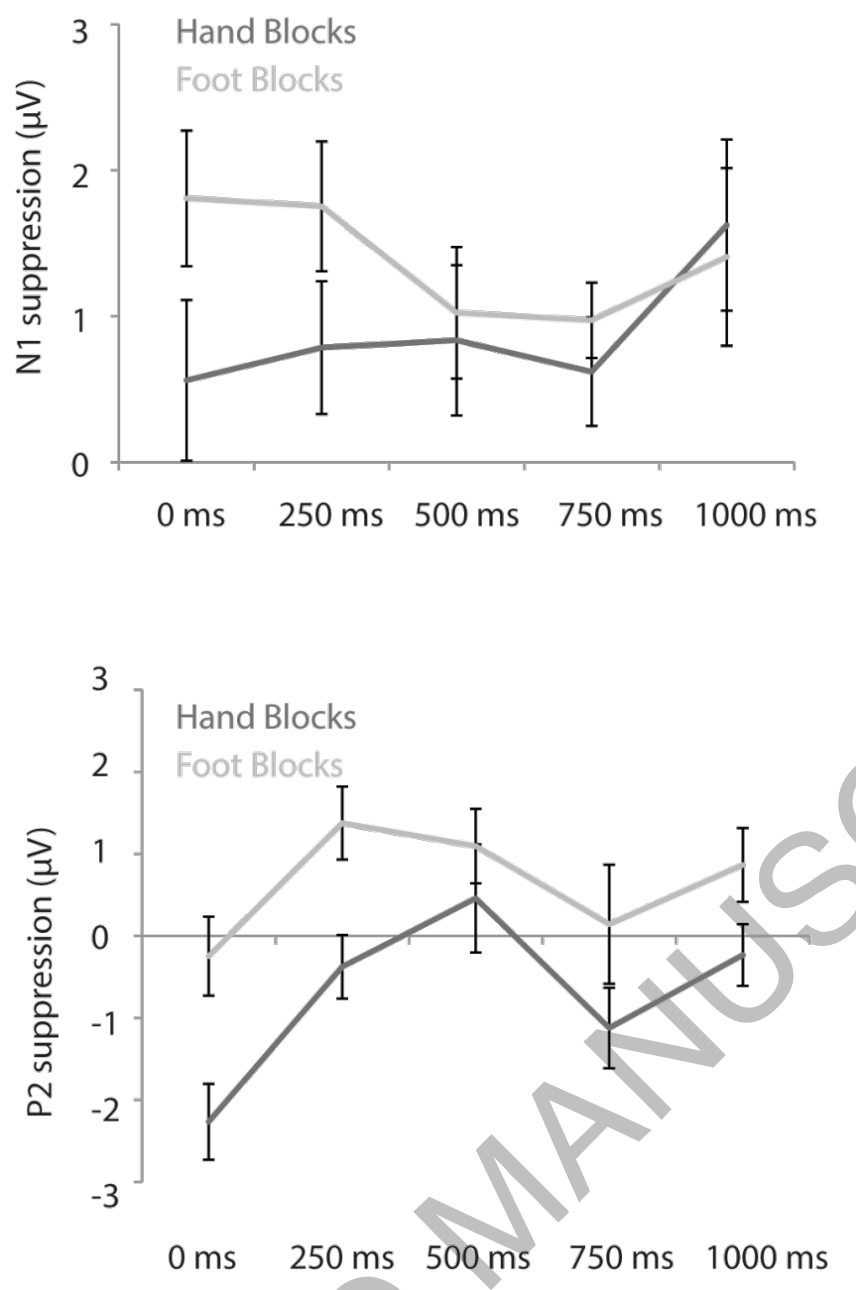

Figure 4: Auditory Suppression of the N1 component for the different conditions. The graph represents suppression of the auditory N1 component (upper graph; i.e. difference between action-sound and external-sound condition) and the P2 component (lower graph; i.e. difference between action sound and external-sound condition). Dark lines represent sounds generated by hand button presses, light lines sound by foot button presses. The sound could be delayed with respect to the button press with different intervals $(0 \mathrm{~ms}, 250 \mathrm{~ms}, 500 \mathrm{~ms}, 750 \mathrm{~ms}, 1000 \mathrm{~ms})$. The presented data is corrected for movement-related effects (i.e. the 'action-no sound' condition was subtracted from the 'action sound' condition). 